The role of participative leadership and trust-based mechanisms in eliciting intern performance: Evidence from China

\author{
Dr Alexander Newman \\ School of Business and Economics, Monash University, Melbourne, Australia \\ alex.newman@monash.edu \\ Phillip Rose \\ Curtin Business School, Curtin University, Perth, Australia \\ philiprosenz@gmail.com \\ Prof Stephen T.T.Teo \\ AUT Business School, Auckland University of Technology, Auckland, New Zealand \\ stephen.teo@aut.ac.nz
}




\title{
The Role of Participative Leadership and Trust-Based Mechanisms in Eliciting Intern Performance: Evidence from China
}

\begin{abstract}
In this paper we investigate the relationship between participative leadership and job performance within the internship setting. Based on two-wave survey data obtained from 309 interns and their supervisors, we find that participative leadership has a positive relationship with job performance and that affective trust mediates that relationship. We also find that although cognitive trust is not significantly related to intern job performance it mediates the relationship between participative leadership and affective trust.
\end{abstract}

Keywords: affective trust; cognitive trust; internships; job performance; participative leadership

\section{INTRODUCTION}

Research on organizational recruitment and selection processes has typically examined the performance of job applicants in maximum performance situations such as job interviews and assessment centres (Zhao \& Liden 2011). However, there is growing evidence to suggest that these forms of recruitment and selection do not necessarily predict job performance post-hire (Posthuma, Moregeson, \& Campion 2003). Only very recently have scholars begun to recognise the importance of alternative tools in the recruitment and selection process such as internships (Zhao \& Liden 2011). Internships have been shown to be a good predictor of the retention and future job performance of applicants, given they allow the organization to measure individual performance in a typical work setting (Gault, Leach, \& Duey 2010). Recent work suggests that job performance of interns is strongly related to their retention, post-hire job performance and career progression (Gault, et al. 2010).

Given these recent insights into the role which intern job performance plays as a predictor of subsequent recruitment and work outcomes, it is important to understand the individual and organizational factors which may lead to its development. Although recent studies have begun to examine the antecedents of intern satisfaction and effectiveness (D'Abate, Youndt, \& Wenzel, 2009; Garavan \& Murphy, 2001; Narayanan, Olk, \& McGrath 2010) there has been limited focus on 
whether the leadership behaviour of supervisors impact on their job performance of interns, and, if so, the mechanisms which underlie its translation.

In the present study we use data from 309 supervisor-intern dyads in Chinese organizations to examine the importance of the supervisor's participative leadership behaviour in engendering higher levels of intern job performance. Although previous studies have found participative leadership to strongly influence the job performance of full-time employees (Huang, Iun, Liu, \& Gong 2010) our study makes an additional contribution by examining the generalizability of this linkage to the context of interns who have limited prior experience in the workplace.

In addition, we examine the trust-based mechanisms which underlie the relationship between participative leadership and performance. Although trust in supervisor has been shown to mediate the impact of participative leadership on job performance, especially for non-managerial employees (Huang et al. 2010) trust has typically been conceptualized as a uni-dimensional construct in prior research. Building on recent developments in the literature which view trust as consisting of two dimensions (Dirks \& Ferrin 2002; Schaubroeck, Lam, \& Peng 2011) one exchange-based (affective trust) and the other cognition-based in nature (cognitive trust), we examine how both dimensions influence intern responses to participative leadership behavior in terms of eliciting higher job performance. The findings of this research should enable organizations to better structure internships which are effective from the point of view of both the organization and the intern.

\section{LITERATURE REVIEW}

\section{Internships}

Prior to graduation students often actively seek internships as a way of sampling organizational life and obtain realistic information about potential employers before making a long-term commitment to a particular career and organization (Linn, Ferguson, \& Egart, 2004). They put students in an experiential learning situation which provides them with an opportunity to apply what they have learnt in the classroom, and interactively develop decision-making skills and understanding of the corporate world (Clark, 2003; Gabris \& Mitchell, 1989; Liu, Xu \& Weitz 2011). 
From an organisational perspective internships are used to evaluate and screen potential hires before deciding whether or not to offer them employment (Gabris \& Mitchell 1989). Recent evidence indicates that the majority of new hires in large multinational firms were their former interns (Zhao \& Liden 2011) and that employees with internship experience receive higher salaries, quicker promotion, and greater job satisfaction and organizational commitment than those without internship experience (Coco 2000; D’Abate 2010; Knouse \& Fontenot 2008).

\section{Internships in the Chinese Context}

Internships have been commonly utilised by China-based organizations as a recruitment and selection tool since the opening-up and reform policy was introduced in 1979. Even in the Maoist era the Chinese government extensively used co-operative education as a means of integrating classroom learning with more vocational experience (Wang 2009). However, over the last two decades the Chinese government has sought to strengthen the effectiveness of co-operative education (Venter 2003) and internships are now a required part on the majority of degree programmes in China in both academic and vocational institutions (Cooke 2005; Wang 2005). Although researchers have begun to examine the importance of internships as a method of recruiting and selecting future employees in China, these studies are typically descriptive in nature (Qiang 1993).

\section{Participative Leadership and Job Performance in the Internship Setting}

Participative leadership refers to a leadership style in which the supervisor encourages their subordinates to take a certain amount of responsibility in the workplace (Somech 2006; Sauer 2011). Through the provision of encouragement, support and influence participative leaders facilitate subordinate involvement in the decision-making process (Amabile, Schatzel, Moneta \& Kramer 2004). Although researchers have begun to investigate the importance of participative leadership to job performance in traditional workplace settings (Huang et al. 2010) no previous research has examined the impact of participative leadership on job performance in the context of internships.

Despite this, over the last 15 years a growing number of studies have highlighted the importance of participative management practices to intern satisfaction and subsequent job 
opportunities (Feldman, Folks, \& Turnley 1999; Rothman 2007). For example, Rothman (2007) found that interns wanted to be provided with more opportunities by their supervisor to participate in challenging work, and get involved in decision-making and the coordination of projects. Researchers have also found that early career graduates are more receptive to the participative behaviour of managers, as they are highly focused on developing their careers (Helmreich et al., 1986). This suggests that the participative leadership of the supervisor might be an important factor behind individual performance in an internship setting.

Given that most of the research investigating the impact of participative leadership type behaviours on internship outcomes has been conducted using Western samples, little is known as to their effectiveness in the Chinese or wider Asian context. Some researchers have been critical of the use of participative management styles in China given that it is a high power-distance culture in which autonomy and participation in decision-making are not highly valued by employees (Eylon \& Au 1999; Zhang \& Begley 2011). However, participative leadership styles are arguably viewed more favourably by the younger generation of Chinese employees given their changing social values. The new generation of Chinese are less respectful of hierarchy and more willing to take the initiative than the older generation (Farh, Hackett \& Liang 2007; Humborstad, Humborstad, Whitfield \& Perry 2008). Indeed, recent work reveals that younger employees with short tenure respond more positively to participative leadership styles (Huang, Shi, Zhang \& Cheung 2006), and that participative leadership positively influences the job performance of non-managerial employees through engendering higher levels of trust (Huang et al. 2010). Despite this no previous work has examined the importance of participative leadership to the job performance of temporary employees such as interns, and the mechanisms which underlie this relationship.

Given that participative mentoring from the supervisor, in terms of providing the intern with autonomy and challenging assignments, has been shown to facilitate interns' socialization and learning outcomes (Feldman, Folks \& Turnley 1999; Beenen \& Rousseau, 2010) we propose that the participative leadership behavior of the supervisor will positively influence the job performance of interns. This leads us to the following hypothesis:

Hypothesis 1. Participative leadership is positively related to intern job performance 


\section{Trust-Based Mechanisms by which Participative Leadership Influences Job Performance}

There is growing evidence to suggest that participative leadership influences the job performance of subordinates through engendering higher levels of trust in supervisor, especially for employees in non-managerial positions (Huang et al. 2010). Despite this, previous work has typically conceptualized trust as a uni-dimensional construct (Huang, et al. 2010). Building on recent developments in the literature, we investigate the mediating effects of trust on the relationship between participative leadership and intern job performance, by conceptualizing trust as consisting of two dimensions, one exchange-based and the other cognition-based in nature, namely affective and cognitive trust (McAllister 1995; Dirks \& Ferrin 2002).

Affective trust refers to that which results from the emotional ties developed between two parties within a relationship as they engage in a process of reciprocal social exchange (Schaubroeck, Lam, \& Peng 2011). By providing opportunities and support to take responsibility and participate in decision-making, participative leaders should elicit affective trust in their subordinates through the development of a close emotional bond between the two parties (Huang et al. 2010). This should make subordinates more comfortable to offer their suggestions and get involved in the process of decision-making, and lead them to reciprocate by engaging in work-related behaviors desired by the supervisor such as job performance (Dirks \& Ferrin 2002).

In contrast, cognitive trust refers to that which develops as a result of the subordinate's perceptions of their leader's characteristics such as their competence, reliability and integrity (Yang, Mossholder \& Peng 2009; Wang, Tomlinson \& Noe 2010). Participative leadership should nurture high levels of cognitive trust in subordinates, as its provision is likely to influence their perceptions of their supervisor's knowledge, skills and competency in dealing with task-related problems. For example, by encouraging participation in decision-making, supervisors should make their subordinates feel more confident in their ability and competence to guide their task performance (Dirks \& Ferrin 2002). This should in turn lead subordinates to judge their work experiences favorably and be more willing to engage in behavior that benefits the organization such as higher levels of job performance (Schaubroeck et al. 2011). 
Based on these theoretical explanations there is a growing empirical literature which investigates how both dimensions of trust influence subordinate responses to the leadership behavior of their supervisors. Recent work suggests that both affective and cognitive trust may both have a positive influence on the behavioral responses of subordinates to leadership behavior which stresses employee participation (Schaubroeck et al. 2011). This leads us to the following hypotheses:

Hypothesis 2. Affective trust mediates the relationship between participative leadership and intern job performance

Hypothesis 3. Cognitive trust mediates the relationship between participative leadership and intern job performance

However, another stream of literature suggests that affective trust may have stronger effects on job performance than cognitive trust given that it is more closely linked to social exchange formulations (Ng \& Chua 2006; Yang \& Mossholder 2010). In other words it may be viewed as a deeper form of trust given it is characterized by strong emotional ties involving the mutual display of care and concern between the supervisor and the subordinate (Wang et al. 2010). However, there is also literature to suggest that cognitive trust may be more important to work outcomes in the early stages of relationship development, and may therefore be an important pre-requisite to the development of affective trust amongst subordinates (Schaubroeck et al. 2011). Cognitive trust should be especially important to the development of affective trust and subsequent performance outcomes in the internship setting, given the limited history of interaction between the supervisor and intern. Where supervisors encourage interns to take responsibility and participate in decision-making, interns are more likely to have positive perceptions of their internship experience and feel confident in their supervisor's ability to guide their task performance. This should lead them to feel safer to engage in social exchange with their supervisor and other members of the organization, and exhibit higher levels of affective trust accordingly. This leads us to the following hypothesis:

Hypothesis 4. Cognitive trust mediates the relationship the relationship between participative leadership and affective trust. 


\section{METHODOLOGY}

\section{Sample and Data Collection Procedure}

Intern participants were undergraduate business majors and recruited through the careers offices of three universities located in the South-East of China. They were required to do internships as part of their degree course for a period of between three to six months. A paper-based survey was distributed to interns halfway through their internship (Time 1) in which they rated the participative leadership of their supervisor and their trust in supervisor. At the same time they were asked to provide their demographic information, information on the organization in which the internship was conducted, and the e-mail contact details of their supervisor. At time 2, at the end of their internship, we contacted their supervisor and asked them to fill out a survey online in which they rated the job performance of the intern. A total of 1019 surveys were distributed to interns of which 506 replied, amounting to a response rate of 49.7 per cent. Out of the 506 surveys distributed to supervisors 309 were returned, amounting to a response rate of 61.1 per cent. This left us with data for 309 intern-supervisor dyads on which analysis could be conducted.

Among the interns, 199 (64.4 per cent) were female, and their mean age was 21.30 years. $53.4 \%$ received payment for their internships. The internship organisations were representative of a diverse range of industrial sectors, including manufacturing (13.6\%), information technology, (3.6\%), finance/banking $(30.7 \%)$, other services $(14.2 \%)$, government $(5.5 \%)$, international trade $(9.1 \%)$, retail $(3.6 \%)$ and education $(4.2 \%)$.

\section{Measures}

Prior to distribution, the back translation process (Brislin 1981) was utilized to translate the English version of the survey into Chinese. All items were measured on a Likert scale of 1-7 (where $1=$ strongly disagree to $7=$ strongly agree). Table 1 shows the means, standard deviations, and bivariate correlations of all variables in the study.

Insert Table 1 about here 


\section{Participative Leadership}

Arnold, Arad, Rhoades and Drasgow's (2000) six-item scale was used to measure the participative leadership of supervisors by interns. Sample items are 'I am encouraged by my immediate supervisor to express ideas/suggestions'. The Cronbach Alpha for this scale was 0.80 .

\section{Affective and Cognitive Trust}

The affective and cognitive trust of interns was self-rated using McAllister's (1995) 5 and 6 item affect and cognition-based trust scales. Sample items included 'We have a sharing relationship'. The Cronbach Alphas for these scales were 0.91 and 0.83 .

\section{Intern Job Performance}

Intern job performance was rated by the intern supervisor using the 4-item in-role performance scale adapted from Farh and Cheng (1997). Sample items are 'this intern made a significant contribution to the overall performance of our work unit'. The Cronbach Alpha for this scale was 0.84 .

\section{Analysis and Results}

First, a confirmatory factor analysis (CFA) was undertaken on all items included in the measurement model through the use of LISREL 8.80. The goodness-of-fit statistics for the hypothesized 4-factor measurement model provided adequate fit to the data $\left(X^{2}=401.63\right.$; d.f. $=146 ;$ IFI $=0.96 ; C F I=0.96$; RMSEA $=0.07)$. A single factor model provided poor fit to the data $\left(X^{2}=1705.50\right.$; d.f. $=152 ;$ IFI $=$ 0.78; $\mathrm{CFI}=0.78 ; \mathrm{RMSEA}=0.18$, with a significant deterioration in chi-square compared with the hypothesized model (change in $X^{2}=1303.87$; change in d.f. $=6 ; p<0.01$ ). Given the fit index recommendations of $\mathrm{Hu}$ and Bentler (1999) the measurement model was considered good enough to proceed with hypothesis testing.

Second, structural equation modelling (SEM) was conducted using LISREL 8.80 to test the study's hypotheses. We initially examined the direct effects of participative leadership on intern job performance. In line with hypothesis 1 participative leadership was found to influence intern job performance to a high degree of significance $(\beta=.54, p<.01)$. Following this, we ran a full mediation model in which paths were drawn from participative leadership to both cognitive and 
affective trust and from both dimensions of trust to intern job performance, and a partial mediation model in which a direct path was added between participative leadership and intern job performance. Although in the full mediation model significant path coefficients were found from participative leadership to both affective $(\beta=.50, p<.01)$ and cognitive trust $(\beta=.63, p<.01)$ and from affective and cognitive trust to intern job performance $(\beta=.24, p<.01, \beta=.28, p<.01)$, when the direct path was added in the partial mediation model, the path between cognitive trust and intern job performance was no longer significant, and the direct relationship between participative leadership and intern job performance was highly significant $(\beta=.48, p<.01)$. Given that the paths between participative leadership and affective trust $(\beta=.50, p<.01)$, and affective trust and intern job performance $(\beta=.12$, $p<.10$ ) were significant, affective trust was found to partially mediate the relationship between participative leadership and intern job performance, in line with hypothesis 2 . In addition, the goodness-of-fit statistics were significantly better for the partial mediation model $\left(X^{2}=456.85\right.$; d.f. $=$ $148 ; \mathrm{IFI}=0.96 ; \mathrm{CFI}=0.96 ; \mathrm{RMSEA}=0.08)$ than the full mediation model $\left(\mathrm{X}^{2}=436.21 ;\right.$ d.f. $=147$; IFI $=0.96 ;$ CFI $=0.96 ;$ RMSEA $=0.08)$, suggesting the partial mediation model fitted the data better. Given that cognitive trust was not found to mediate the relationship between participative leadership and intern job performance contrary to Hypothesis 3 , we tested the mediating effects of cognitive trust on the relationship between participative leadership and affective trust (Hypothesis 4) by adding a path from cognitive trust to affective trust. The path from cognitive trust to affective trust was significant $(\beta=.47, p<.01)$ and the path between participative leadership and affective trust fell in significance $(\beta=.17, p<.01)$. This is supportive of hypothesis 4 and suggests that cognitive trust mediated the relationship between participative leadership and affective trust. The goodness-of-fit statistics for the model when the new path was included were $\left(X^{2}=402.21\right.$; d.f. $=147$; IFI $=0.96$; CFI $=0.96$; RMSEA $=0.07$ ), and better than the model without the direct path. The significant paths of the final model are presented in Figure 1.

Insert Figure 1 about here

Third, in order to provide more confidence in our mediation results, bootstrapping was used to calculate the indirect effects of participative leadership on intern job performance through affective 
trust, and participative leadership on affective trust through cognitive trust (Preacher \& Hayes 2008). We found that the indirect effects of participative leadership on intern job performance via affective trust were significant (estimate $=.08, p<.01$ ), and that the indirect effects of participative leadership on affective trust via cognitive trust were significant (estimate $=.25, p<.01$ ). These results provide further support for hypotheses 2 and 4.

\section{Discussion}

Despite the pervasive use of internships, and their proven ability to generate mutually beneficial outcomes for both interns and organisations, there is little in the way of research investigating the specific mechanisms which underpin the achievement of these outcomes. Our study is the first to substantiate the generalizability of the positive linkages between participative leadership and subordinate performance found in other employee settings (Huang et al. 2010) to the internship setting. In this employment context our findings also revealed that affective trust partially mediated the impact of participative leadership on intern job performance, but cognitive trust had no mediating effects at all. However, cognitive trust was found to mediate the relationship between participative leadership and affective trust. This provides support for the growing stream of literature highlighting the distinctive influence of affective and cognitive dimensions of trust on workplace outcomes, corroborating previous research findings that affective trust has positive effects on job performance whilst cognitive trust has non-significant or weaker effects (Ng \& Chua 2006; Yang \& Mossholder 2010). This may result from the fact that affective trust is more closely linked to social-exchange processes than cognitive trust. However, our study also made a distinct theoretical contribution to the existing literature by demonstrating that cognitive trust is a necessary prerequisite to the development of affective trust, i.e. if subordinates do not have cognitive trust it is unlikely they will feel safe to engage in social exchange with their supervisor and develop an emotional bond (affective trust).

This study makes further contributions related to the particular workplace and cultural context of the research. The role of cognitive trust as a precondition for affective trust substantiates previous work investigating the importance of supervisory-level employees to the organizational entry of comparative non-regular employee groups, including temporary employees and newcomers. For such 
employee groups organisational entry has been found to be characterized by uncertainty, incomplete information and limited access to resources. In such a situation the supervisor plays a focal role in reducing uncertainty and providing necessary support during organisational entry (Ashforth \& Saks 1996; Kim, Cable \& Kim, 2005). If interns feel that their supervisor is competent they are likely to develop high levels of cognitive trust. This provides them with the necessary preconditions for the development of affective trust. Our findings regarding the mediating effects of cognitive trust on the relationship between participative leadership and affective trust is of high relevance to research investigating other non-regular employment settings (De Cuyper et al. 2008).

Our findings also support those from previous work which highlights the importance of strong supervisor-subordinate guanxi relationships, based on reciprocity and mutual trust, to organisational outcomes (Cheung, Wu, Chan \& Wong 2009; Chen("Chen, Tsui, Farh - 2002 - Loyalty to supervisor vs. organizational commitment Relationships to employee performance in China.pdf,"), Tsui \& Farh 2002). Additionally, our study diverges from research questioning the appropriateness of participative leadership practices in the Chinese organisational context (Farh \& Cheng 2000).

A number of managerial implications may be drawn from this study. First, our findings clearly indicate that organizations should invest in the development of internship programmes which stress intern participation and assign interns to supervisors who have a predisposition for participative leadership behaviours. In addition, organizations should consider providing supervisors with training to enhance participative leadership behaviours and design internships to facilitate intern participation. This should enable organisations to establish which interns have the potential to respond positively to participative leadership behaviour in the post-hire period.

\section{Limitations and Suggestions for Future Research}

A number of limitations should be taken into account when making generalizations based on the findings of the current study. Although the sample spanned numerous organizations, industries and ownership categories, the interns were all students within business schools located in a relatively economically developed region of China. Hence these findings may not generalize to students in other academic fields or geographic locations in China. Although our study used data from multiple sources 
in two waves it was hardly longitudinal in nature given that only a short time separated the data collection from interns and their supervisors. In future research could be conducted over a longer time frame. 


\section{REFERENCES}

Amabile M, Schatzel EA, Moneta GB and Kramer SJ (2004) Leader behaviors and the work environment for creativity: Perceived leader support, Leadership Quarterly 15(1): 5-32.

Arnold JA, Arad S, Rhoades JA and Drasgow F (2000) The empowering leadership questionnaire: The construction and validation of a new scale for measuring leader behaviors, Journal of Organizational Behavior 21(3): 249-269.

Ashforth, BK and Saks AM (1996) Socialization tactics: Logitudinal effects on newcomer adjustment, Academy of Management Journal 39(1): 149-178.

Beenen G and Rousseau DM (2010) Getting the most from MBA internships: Promoting intern learning and job acceptance, Human Resource Management 49(1): 3-22.

Brislin RW (1981) Translation and content analysis of oral and written material in HC Triandis and Berry JW (Ed.), Hand Book of Cross Cultural Psychology, Vol. 1: 389-444, Allyn \& Bacon, Boston, M.A.

Chang HT and Chi NW (2007) Human resource managers' role consistency and HR performance indicators: The moderating effect of interpersonal trust in Taiwan, International Journal of Human Resource Management 18(4): 665-683.

Chen Z, Tsui AS and Farh JL (2002) Loyalty to supervisor vs organizational commitment: relationships to employee performance in China, Journal of Occupational and Organizational Psychology 75(3): 339-356.

Cheung FY, Wu WP, Chan KK and Wong ML (2009) Supervisor-subordinate guanxi and employee work outcomes:The mediating role of job satisfaction, Journal of Business Ethics 88(Supplement 1): 77-89.

Clark SC (2003) Enhancing the educational value of business internships, Journal of Management Education 27(4): 472- 484.

Coco M (2000) Internships: A try before you buy arrangement, SAM Advanced Management Journal 65(1): $41-47$. 
Cook SJ, Parker RS and Pettijohn CE (2004) The perceptions of interns: A longitudinal case study, Journal of Education for Business 79(1): 179-185.

Cooke FL (2005) Vocational and enterprise training in China: Policy, practice and prospect. Journal of the Asia Pacific Economy 10(1): 26-55.

De Cuyper N, De Jong J, De Witte H, IIsaksson K, Rigotti T and Schalk R (2008) Literature review of theory and research on the psychological impact of temporary employment: To-wards a conceptual model, International Journal of Management Reveiws 10(1): 25-51.

Ding Z and Ng F (2007) Reliability and validity of the Chinese version of McAllister's trust scale, Construction Management and Economics 25(11): 1107-1117.

Dirks KT and Ferrin DL (2002) Trust in leadership: Meta-analytic findings and implications for research and practice, Journal of Applied Psychology 87(4): 611-628.

D'Abate CP (2010) Developmental interactions for business students: Do they make a difference?, Journal of Leadership \& Organizational Studies 17(2): 143-155.

D'Abate CP, Youndt MA and Wenzel KE (2009) Making the most of an internship: An empirical study of internship satisfaction, Academy of Management Learning \& Education 8(4): 527 538.

Eylon D and Au K (1999) Exploring empowerment cross-cultural differences along the power distance dimension, International Journal of Intercultural Relations 23(3): 373-385.

Farh JL and Cheng BS (2000) A cultural analysis of paternalistic leadership in Chinese organizations, in Li JT, Tsui AS and Weldon E (Ed), Management and Organizations in the Chinese Context, pp85-127, Macmillan, London.

Farh JL, Hackett RD and Liang J (2007) Individual-level cultural values as moderators of perceived organizational support-employee outcomes relationships in China: Comparing the effects of power distance and traditionality, Academy of Management Journal 50(3): 715-729.

Farh JL, Leung F and Law K (1998) On the cross-cultural validity of Holland's model of vocational choices in Hong Kong, Journal of Vocational Behavior 52(3): 425-440.

Feldman DC, Folks WR and Turnley WH (1999) Mentor-protégé diversity and its impact on international internship experiences, Journal of Organizational Behavior 20(5): 597-611. 
Gabris G and Mitchell K (1989) Exploring the relationships between intern job performance, quality of education experience, and career placement, Public Administration Quarterly 12(4): 484504.

Garavan, TN and Murphy C (2001) The co-operative education process and organisational socialisation: a qualitative study of student perceptions of its effectiveness, Education + Training 43(6): 281-302.

Gault J, Leach E and Duey M (2010) Effects of business internships on job marketability: the employers' perspective, Education + Training. 52(1): 76-88.

Harzing AW (2006) Response styles in cross-national survey research: A 26-country study, International Journal of Cross Cultural Management 6(2): 243-266.

Helmreich R, Sawvin L and Carsrud A (1986) The honeymoon effect in job performance: Temporal increases in the predictive power of achievement motivation, Journal of Applied Psychology 71(2): 185-188.

Huang X, Shi, K, Zhang Z and Cheung YL (2006) The impact of participative leadership behavior on psychological empowerment and organizational commitment in Chinese state-owned enterprises: the moderating role of organizational tenure, Asia-Pacific Journal of Management 23: 345-367.

Huang X, Iun J, Liu A and Gong Y (2010) Does participative leadership enhance work performance by inducing empowerment or trust? The differential effects on managerial and nonmanagerial subordinates, Journal of Organizational Behavior 31(1): 122-143.

Humborstad SIW, Humborstad B, Whitfield R and Perry, C (2008) Implementation of empowerment in Chinese high power-distance organizations, International Journal of Human Resource Management 19(7): 1349-1364.

Kim TY, Cable DM and Kim SP (2005) Socialization tactics, employee proactivity, and person organization fit, Journal of Applied Psychology 90: 232-241.

Knouse SB and Fontenot G. 2008. Benefits of the business college internship: A research review, Journal of Employment Counseling, 45(1): 61-66. 
Lam S, Chen XP and Schaubroeck J (2002) Participative decision making and employee performance in different cultures: The moderating effects of allocentrism/idiocentrism and self-efficacy, Academy of Management Journal 45: 905-914.

Linn PL, Ferguson J and Egart K (2004) Career exploration via cooperative education and lifespan occupational choice, Journal of Vocational Behavior 65(3): 430-447.

Liu Y, Xu J and Weitz BA (2011) The role of emotional expression and mentoring in internship learning, Academy of Management Learning and Education 10(1): 94-110.

McAllister DJ (1995) Affect- and cognition-based trust as foundations for interpersonal cooperation in organizations, Academy of Management Journal 38(1): 24-59.

Narayanan VK, Olk PM and Fukami C (2010) Determinants of internship effectiveness: An exploratory model, Academy of Management Learning and Education 9(1): 61-80.

Ng KY and Chua RYJ (2006) Do I contribute more when I trust more? Differential effects of cognition- and affect-based trust, Management and Organization Review 2(1): 43-66.

Posthuma RA, Moregeson FP and Campion MA (2002). Beyond employment interview validity: A comprehensive narrative review of recent research and trend over time, Personnel Psychology 55(10): $1-81$.

Preacher KJ and Hayes AF (2008) Asymptotic and resampling strategies for assessing and comparing indirect effects in multiple mediator models, Behavior Research Methods 40(3): 879-891.

Qiang LD (1993) The forms of cooperative education and their key elements, Journal of Cooperative Education 29(Fall): 53-60.

Rothman M (2007) Lessons learned: Advice to employers from interns, Journal of Education for Business 82(3): 140-144.

Sauer SJ (2011) Taking the reins: The effects of new leader status and leadership style on team performance, Journal of Applied Psychology 96(3): 574-587.

Somech A (2006) The effects of leadership style and team process on performance and innovation in functionally heterogeneous teams, Journal of Management 32(1): 132-157. 
Venter K (2003) Building on formal education: employers' approaches to the training and development of new recruits in the People's Republic of China, International Journal of Training and Development 7(3): 186-202.

Wang S, Tomlinson EC and Noe R (2010) The role of mentor trust and protégé internal locus of control in formal mentoring relationships, Journal of Applied Psychology 95: 358-367.

Wang, VCX (2005) Teaching philosophies of Chinese vocational education instructors, International Journal of Vocational Education and Training 13(1): 7-21.

Wang VCX (2009) China's vocational education: An insider's views in light of western vocational education, The International Journal of Vocational Education and Training 17(1): 108-120.

Yang J, Mossholder KW and Peng TK (2009) Supervisory procedural justice effects: The mediating roles of cognitive and affective trust, Leadership Quarterly 20, 143-154.

Zhang Y and Begley TM (2011) Power distance and its moderating impact on empowerment and team participation, International Journal of Human Resource Management 22(17):3601-3617. 
Table 1: Descriptive Statistics, Correlations amongst Study Variables and Reliability Coefficients

\begin{tabular}{lllllll}
\hline Variable & Mean & S.D. & $\begin{array}{l}\text { Participative } \\
\text { leadership }\end{array}$ & $\begin{array}{l}\text { Affective } \\
\text { trust }\end{array}$ & $\begin{array}{l}\text { Cognitive } \\
\text { trust }\end{array}$ & $\begin{array}{l}\text { Intern Job } \\
\text { Performance }\end{array}$ \\
\hline $\begin{array}{l}\text { Participative } \\
\text { leadership }\end{array}$ & 4.88 & 0.95 & $(0.80)$ & & & \\
$\begin{array}{l}\text { Affective } \\
\text { trust }\end{array}$ & 4.58 & 1.14 & $.420^{* *}$ & $(0.91)$ & & \\
$\begin{array}{l}\text { Cognitive } \\
\text { trust }\end{array}$ & 5.08 & 0.89 & $.498^{* *}$ & $.519^{* *}$ & $(0.83)$ & \\
$\begin{array}{l}\text { Intern job } \\
\text { performance }\end{array}$ & 4.77 & 1.07 & $.481^{* *}$ & $.333^{* *}$ & $.347^{* *}$ & $(0.84)$ \\
\hline
\end{tabular}

$* p<.05, * * p<.01$

Numbers in parentheses are the coefficient alphas. 
Figure 1: Final Model-

Results of Structural Equation Modeling

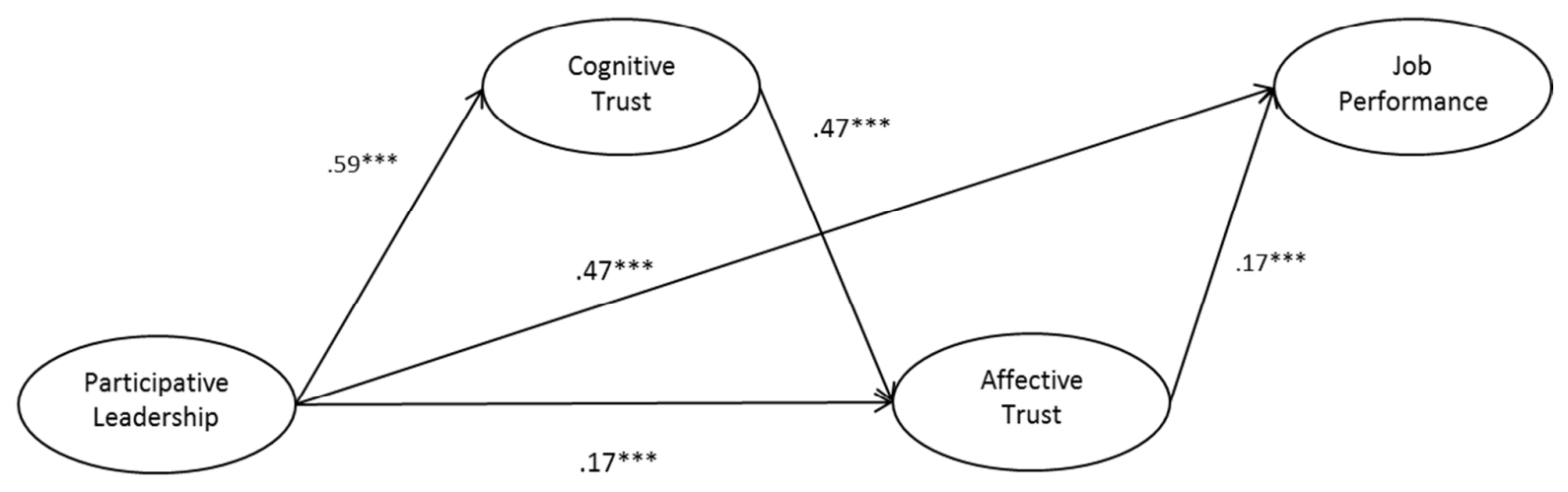

${ }^{*} p<.05 ; * * p<.01 ; * * * p<.001$ 